\title{
A Study of the Influence of the Intercooled Turbocharger and Cooled Exhaust Gas Recirculation on the Performance Parameters of an Ethanol-fueled Engine
}

\author{
A. P. Mattos ${ }^{1} *$ W. L. R. Gallo ${ }^{2}$ \\ ${ }^{1}$ Federal University of Pará, Instituto de Tecnologia, Guamá, 66075-110 Belém, Brazil \\ ${ }^{2}$ University of Campinas, Cidade Universitária “Zeferino Vaz”, 13083-970 Campinas, Brazil \\ E-mail: ${ }^{1}$ anapmattos@ufpa.br, ${ }^{2}$ gallo@ @em.unicamp.br
}

Received 20 December 2018, Revised 08 August 2019, Accepted 21 August 2019

\begin{abstract}
The hydrous ethanol combined with the turbocharged engine with Exhaust Gas Recirculation (EGR) was investigated with a phenomenological simulation model. This paper analyzes the influence of the low pressure, high pressure cooled EGR, the intercooler, and the amount of recirculated gases on the performance parameters in a spark-ignited ethanolfueled engine. Using a phenomenological model developed in Matlab ${ }^{\circledR}$, the behavior of the pressure and temperature curves is analyzed considering the variation of the crank angle, the formation of $\mathrm{NO}_{\mathrm{x}}$, and the tendency for knocking. The fuel analyzed is hydrous ethanol (E95h - 5\% water by volume), which is widely used in Brazil. The proposed technique showed an increased power using the intercooler (IC) while avoiding knocking. This study showed that the use of a cooled EGR and turbocharged SI results in increased power, while also reducing $\mathrm{NO}_{\mathrm{x}}$ formation, and preventing or reducing engine knocking. In some engines, the low pressure cooled EGR is better than high pressure, but this can be different for another engine. The model helps to find the best option for each engine modeled.
\end{abstract}

\section{Keywords: Cooled EGR; turbocharger; hydrous ethanol; phenomenological model of spark engine.}

\section{Introduction}

The simulations of processes in engines make a significant role in the conception and development of the new technologies for better performance and decreased emissions. For this, the objective of this work is to study the performance of a turbocharged engine with exhaust gas recirculation (EGR) using hydrous ethanol.

Ethanol has been utilized in Brazil as a commercial fuel in the vehicles since 1979. E27 (gasoline with 27\% v/v ethanol) and E95h (ethanol with 5\% v/v water) are the commercially available fuels for spark-ignition engines. The majority of flex-fuel vehicles work well with mixtures of gasoline and ethanol and, in Brazil, nearly $90 \%$ of the automobile production in the last 10 years adopts flex-fuel engines.

In the United States E85 is adopted, which is a mixture of $85 \%$ ethanol and $15 \%$ gasoline. More than six millions of vehicles in EUA are flex fuel vehicles (FFVs)[1].

Ethanol possesses properties which make it attractive for turbocharged engines when compared with gasoline. Octane number is the most known. Other of these properties is the heat of vaporization: $841 \mathrm{~kJ} / \mathrm{kg}$ vs. $360 \mathrm{~kJ} / \mathrm{kg}$ for ethanol and gasoline, respectively. Therefore, due to the different stoichiometric air/fuel ratio, the amount of available energy per $\mathrm{kg}$ of a stoichiometric mixture to cool the load is 84.1 $\mathrm{kJ} / \mathrm{kg}$ vs. $23 \mathrm{~kJ} / \mathrm{kg}$ respectively. It offers better cooling of the cylinder load in both naturally aspirated engines and turbocharged engines [2].

Low engine speed and high temperatures in the unburned mixture can induce to knocking. Ethanol is widely used as a fuel due to its anti-knocking properties. Ethanol has an effective octane value rating of Research Octane Number (RON) 129 and Motor Octane Number (MON) 102 [3]. Since ethanol has much higher octane number than gasoline, ethanol-fueled engines admit higher compression ratios and greater power in turbo engines, as well as better auto-ignition limits[4].

EGR was introduced to vehicles in the 1970s and sought to reduce $\mathrm{NO}_{\mathrm{x}}$ emissions, as this reduces temperatures in the combustion chamber [5]. The NOx formation mechanism arises from thermal processes, which depend on temperature. Three popular explanations for the effect of EGR on $\mathrm{NO}_{\mathrm{x}}$ reduction are increased ignition delay, increased heat capacity, and dilution of the intake charge with inert gases [6].

Currently, EGR is employed in turbocharged engines to control of engine knocking, and more power in critical conditions [7], [8]. Knocking is one of the main problems in improving spark ignition efficiency [9]. Especially for technologies like downsizing and downspeeding, high compression rates are adopted to decrease $\mathrm{CO}_{2}$ emissions, and frequently the engine enters the knocking barrier [10], [11].

The purpose of this study is to present how each equipment, cooling EGR, low and high pressure EGR system, and turbocharger intercooler influence the performance parameters of the engine. The parameters studied affected the performance of the engine, especially with regard on the impact on knocking tendency and the formation of $\mathrm{NO}_{\mathrm{x}}$. This objective is achieved by using a phenomenological model for spark ignition engines. The model was validated for the aspirated engine with experimental data [12]. To model the turbocharged engine data of literature was utilized.

\subsection{Cooled EGR}

The exhaust gas recirculation system may be classified according to its temperature or its pressure. In rankings based on temperature, one finds the Hot EGR, the Fully cooled EGR, and the Partly cooled EGR. In classifications based on 
pressure, one finds either the high-pressure EGR (HP) or the low-pressure EGR (LP). The LP ERG system is located before the compressor, and the HP EGR cooler is situated before the turbine inlet [5], [7]. The EGR - HP system is sometimes also called Short Route and the LP a Long Route [6]. This study explored both options to choose the better option for the simulated engine.

The determination of amount of gases to be recirculated was also an essential aspect of this study, as each type of engine possesses an optimal mass to be recirculated for each particular load condition, speed, and $\lambda$. Generally speaking, a 15\% EGR flow has a significant effect by reducing knocking and the allowing the engine to operate at compression ratios as high as 12 [13]. Higher EGR flow levels also serve to reduce $\mathrm{NO}_{\mathrm{x}}$ and $\mathrm{CO}$. However, there is also a loss in combustion efficiency with instability and increased formation of hydrocarbons (HC) [11], [14].

The EGR recirculation percentage influences many parameters of the engine performance, as highlighted in a study by Alger [11], which shows an average reduction of $75 \%$ in the emissions of $\mathrm{NO}_{x}$, in both GDI and PFI (Port Fuel Injection), when there is an increase of 0 to $30 \%$ in EGR recirculation. However, there is an increase of $50 \%$ to $60 \%$ in $\mathrm{HC}$ emissions, but a $25 \%$ to $33 \%$ reduction in $\mathrm{CO}$ emissions in GDI and PFI. The amount of recirculated EGR affects the specific heat ratio and the peak temperature. The larger is the EGR percentage, the lower the peak temperature. It is for this reason that there is a smaller quantity of thermal $\mathrm{NO}_{\mathrm{x}}$ formed, as expected. However, this translates to a reduction in engine power.

\subsection{Turbocharger}

The main reason for using a turbocharger is to increase the power of the engine. However, one must be careful when using turbochargers, as rising temperatures and pressures may cause a knocking or a non-optimal ignition after the initial spark plug ignition. A solution to this problem would be to cool the mixture via an intercooler after the compressor (IC) and this heat exchanger can function with water or air as a cooling fluid [15].

The intercooler is a compact cross-flow heat exchanger in which the fluids are not mixed. This equipment is the best ally of turbocharged engines, as it is responsible for cooling the air + EGR mixture, leaving the compressor with a higher mass density, resulting in a better burning efficiency and higher engine efficiency.

The wastegate valve (WG) is another part of the turbocharger system. This is a flow discharge valve used to control the flow through the turbine, and thus, the turbocharger load [16].

\section{Methodology}

The turbocharger and EGR system model was implemented in a two-zone phenomenological model of spark ignition engine. A chemical kinetics model was used, developed in a study by Lima [17], as well as the knocking model developed in a research by Junior [18], both belonging to our research group and make use of experimental data to validate their models for the same engine.

The engine under study is a three-cylinder engine, while the simulation model is for a single cylinder. So the mass that passes through the turbocharger both in the intake and exhaust systems is three times the mass admitted by one cylinder. The maximum recirculation gas flow was set at $15 \%$ of the exhaust mass flow and was obtained with the turbocharged engine operating at $6000 \mathrm{rpm}$ under full load since the sizing of the EGR cooler must take into consideration the greater mass flow possible. A $15 \%$ recirculation factor was chosen because Alger [11] points out that this is the maximum quantity for attaining positive EGR effects, as any quantity above this will result in increased $\mathrm{HC}$ formation, reduced burn rate, and increased fuel consumption. However, the recirculation percentage is still a heavily debated issue within the scientific community because it depends on the engine and the specification under which it operates. Chen et al.[10] performed a study with different recirculation percentages for different engine speeds (2600, 3000, and $3600 \mathrm{rpm})$, with test results varying from $6 \%$ to $16 \%$ for SI engines. Nasser [7] in his study of EGR cooler optimization, concluded that the ideal EGR\% was $10 \%$, but systems do operate well up until $15 \%$ of recirculated EGR. However, it should be noted that this was for a Diesel engine.

There are no literature data on SI turbo engines using hydrous ethanol. This study is important to predict how the turbocharged engine will behave when using hydrated ethanol.

\subsection{Modeling the Turbocharger}

Mass and energy balances were used to model the turbocharger. For the modeling, it was necessary to establish hypotheses, since experimental data was not yet available for the turbocharged engine operating with ethanol. So, typical values for gasoline turbocharged engines were used to estimate the exhaust temperature $\left(\mathrm{T}_{3}\right)$ and pressure $\left(\mathrm{P}_{3}\right)$ available to the turbine for each engine speed and load.

Figure 1 shows the schematic of the turbocharger and EGR system that was analyzed; the points present in the next equations are also shown. The model was initially separated by equipment, and the Eqs. of the turbine are presented in Eq. (1) to (4). The Eq. (1) represents the turbine pressure ratio, and Eq. (2) the calculation of the isentropic exit temperature of the turbine, and Eq. (3) the calculate the real output temperature of the turbine.

$$
\begin{aligned}
r p_{t} & =\frac{P_{3}}{P_{4}} \\
T_{4 s} & =T_{3}\left(\frac{1}{r p_{t}}\right)^{\left(\left(K_{\text {gas }}-1\right) / K_{\text {gas }}\right)}
\end{aligned}
$$

The $\mathrm{K}_{\mathrm{gas}}$ is the relation between specific heats for the exhaust products: $\frac{c p_{\text {gas }}}{c v_{\text {gas }}}$.

$$
T_{4}=T_{1}-\eta_{t}\left(T_{3}-T_{4 S}\right)
$$

By performing energy balance between the turbine and the compressor, one arrives at Eq. (4), which is expanded to Eq. (5).

$$
\begin{aligned}
& \dot{W}_{c}=\dot{W}_{t} \eta_{m} \\
& \dot{m}_{c o m p} c p_{\text {mix }}\left(T_{2}-T_{1}\right)=\dot{m}_{t} c p_{g}\left(T_{3}-T_{4}\right) \eta_{m}
\end{aligned}
$$

Where: $\mathrm{cp}_{\mathrm{g}}$ is the specific heat at constant pressure for the combustion gases, $\mathrm{cp}_{\text {mix }}$ is the specific heat at constant pressure for the air and EGR mixture, $\eta_{\mathrm{m}}$ is the turbocharger mechanical efficiency, $\dot{m}_{t}$ the mass flow that passes through the turbine, and $\dot{m}_{\text {comp }}$ the mass flow of air + EGR that passes through the compressor.

Isolating the output temperature of the compressor of Eq. (5), one arrives at Eq. (6).

$$
T_{2}=\frac{W_{t} \eta_{m}}{m_{\text {comp }} c_{p_{\text {mix }}}}+T_{1}
$$


Eq. (7) represents the calculation of the isentropic temperature of the compressor by the efficiency of the compressor $\left(\eta_{\mathrm{c}}\right)$.

$$
T_{2 s}=\frac{\left(T_{2}-T_{1}\right)}{\eta_{c}}+T_{1}
$$

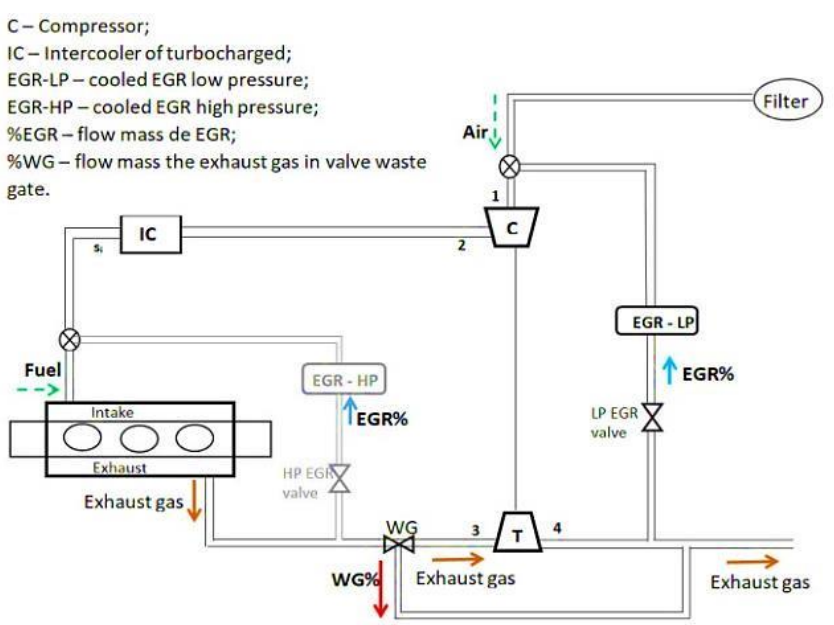

Figure 1. Schematic design of the turbocharger with the low and high pressure EGR systems.

Finally, the calculations of the compressor pressure ratio and the output pressure are given in Eq. (8) and (9), respectively.

$$
\begin{aligned}
& \left(\frac{T_{2 s}}{T_{1}}\right)^{K_{M I S T} / K_{M I S T}-1}=r p_{c} \\
& P_{2}=P_{1} r p_{c}
\end{aligned}
$$

For the LP EGR system, the $\mathrm{K}_{\text {mist }}$ is the ratio between $\mathrm{c}_{\mathrm{p}}$ and $c_{v}$ for mixture the air with EGR. For HP EGR system, there is only air in the compressor. The properties are calculated in the function the $c_{p}$ e $c_{v}$ at each composition, for the specific temperature. For the LP EGR system, the input temperature of the compressor is determined by the energy balance between the recirculated gases and air (Eq. 10).

$$
T_{1}=\frac{\dot{m}_{a i r} c_{p, a i r} T_{a i r}+\dot{m}_{E G R} c_{p, E G R} T_{o u t}{ }_{E G R}}{\dot{m}_{\text {air }} c_{p, a i r}+\dot{m}_{E G R} c_{p, E G R}}
$$

The thermodynamic properties of the recirculated gases and air are calculated from a model that was developed to calculate these properties according to the data taken from Janaf tables [19].

Within the turbocharger system, it is necessary to determine the output temperature of the intercooler $\left(\mathrm{T}_{\mathrm{si}}\right)$.

$\mathrm{T}_{\mathrm{si}}$ was determined by the intercooler effectiveness $\left(\varepsilon_{I C}\right)$ and is presented in Eq. (11). The value adopted for $\varepsilon_{I C}$ was $75 \%$.

$$
T_{s i}=T_{2}-\left(T_{2}-T_{0}\right) \varepsilon_{I C}
$$

\subsection{Modelling an EGR cooler}

In this stage, the objective is to determine the parameters of intake and exhaust of the fluids of the heat exchanger, in order to calculate the intake temperature of the compressor for LP EGR system, (Eq.10) or the temperature for the engine intake for HP EGR system.

But it is necessary to calculate also the exhaust

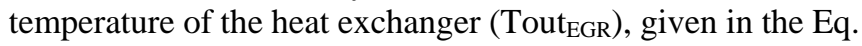
(12). The determination of the temperature of the fluids the heat exchanger was calculated using the effectiveness model, which is found for NTU method.

$$
\text { Tout }_{E G R}=T i_{E G R}-\frac{\varepsilon \dot{q}_{\max }}{C_{E G R}}
$$

Where: $\mathrm{T}_{\text {outEGR }}$ is the temperature of the output of gases of the cooled EGR, $\mathrm{T}_{\mathrm{iEGR}}$ is the input temperature of the gases on the EGR cooler. For EGR low pressure is $T i_{E G R-L P}=T 4-$ $\Delta$, for EGR high pressure is $T i_{E G R-H P}=T 3-\Delta$ where this $\Delta$ is $100^{\circ} \mathrm{C}$, assuming the gases cool along the way. $\mathrm{C}_{\mathrm{EGR}}$ is the capacitance of the recirculated gases and the $\dot{q}_{\max }$ is the maximum heat that can be changed (Eq. 13).

$$
\dot{q}_{\max }=C_{\min }\left(T e_{E G R}-T e_{H 20}\right)
$$

The input water temperature $\left(\mathrm{T}_{\mathrm{iH} 20}\right)$ is $95^{\circ} \mathrm{C}$, which is also radiator coolant water. The EGR system was modeled and used to determine the sizing of the EGR cooler.

In this study, Effectiveness with Number of Transfer Unit's method ( $\varepsilon-\mathrm{NTU})$, was applied to determine the $T_{\text {out }_{E G R}}$ and the number of transfer units (NTU), to determine the area of the heat exchanger.

The heat transfer area was calculated by the NTU method (Eq.14) and by the logarithmic mean temperature method (Eq.15) for the model to converge considering the two methods. The global heat transfer coefficient was calculated by the method of equivalent resistances (Eq.16).

Initially, inputs for effectiveness and the overall coefficient were given to run the model and to find the area of the heat exchanger, as well as to determine the internal diameter, and the number and length of the tubes. The heat exchanger chosen for sizing was the unmixed cross-flow tube bundle exchanger.

$$
\begin{aligned}
& N T U=\frac{U A}{C_{\text {min }}} \rightarrow A=\frac{N T U C_{\text {min }}}{U} \\
& A=\frac{\dot{q}_{\text {real }}}{U \Delta T_{\text {ml }}}
\end{aligned}
$$

where: $\Delta T_{m l}$ is the logarithmic mean of the heat exchanger input and output temperatures, and is calculated by Eq. (16).

$$
\begin{aligned}
& \Delta T_{m l}=\frac{\Delta T_{\text {out }}-\Delta T_{\text {in }}}{\ln \left(\frac{\Delta T_{\text {out }}}{\Delta T_{\text {in }}}\right)} \\
& U=\frac{1}{\frac{1}{h_{i} A_{i}}+\frac{1}{h_{e} A_{e}}+\frac{L}{k A_{i}}+R_{f}}
\end{aligned}
$$

The coefficients for heat transfer by convection $\left(h_{i}\right.$ and $\left.h_{e}\right)$ and conduction (K) were obtained as a function of the Nusselt number and the internal and external thermal conductivity of the tube. $R_{f}$ is the equivalent resistance referring to the incrustations.

Finally, with the cooler size, one can calculate the EGR output temperature of the exchanger (Eq.18) using the method of effectiveness $(\varepsilon)$.

$$
T_{\text {out }_{E G R}}=T i_{E G R}-\frac{\varepsilon \dot{q}_{\max }}{C_{E G R}}
$$

where: $T_{\text {out }}$ EGR is the output temperature of the EGR gases from the heat exchanger (EGR-C),

The effectiveness is calculated by the method of the number of transfer units (NTU) and calculated in Eq. (19) [20].

$$
\varepsilon=1-\left[\exp \left(\frac{N T U^{-0.22}}{C_{r}}\right) \exp \left(-C_{r} N T U^{-0.78}\right)-1\right]
$$

where: $\mathrm{C}_{\mathrm{r}}$ is the ratio between minimum and maximum capacitance.

The methodology for both coolers are the same; the difference is the mass flow though compressor, turbine, and the admission temperature of the mixture by the cylinder.

In the high pressure EGR system, the mixer is situated after the intercooler, where the admission temperature of the engine is obtained by mass and energy balance. For the low 
pressure EGR system, the admission temperature is the output temperature of the intercooler.

\subsection{Low Pressure EGR System}

The mass that compressor admits is the air mass and recirculation gases; thus, the formulation is by Eq. (20).

$$
\dot{m}_{\text {comp }}=3 \dot{m}_{\text {air }}+3 \dot{m}_{E G R}
$$

where the $m_{\text {air }}$ is the air mass flow for a single cylinder. The modeled engine is a three cylinder. The same applies to determine the EGR mass flow, calculated by Eq. (21).

$$
\dot{m}_{E G R}=\left(3 \dot{m}_{\text {air }}+3 \dot{m}_{\text {fuel }}\right) E G R \%
$$

where $m_{\text {fuel }}$ is the fuel mass, EGR\% is the percentage of gases exhaust recirculated; this percentage is the input of the model, which varied from 0 to $15 \%$. Data for air and fuel masses have origins on the phenomenological model for one cylinder.

The mass through the turbine is calculated by Eq. (22).

$\dot{m}_{\text {TURB }}=\left[\left(3 \dot{m}_{\text {air }}+3 \dot{m}_{\text {fuel }}\right)+\dot{m}_{E G R}\right](1-W G)$

where WG is the mass flow fraction through the wastegate valve.

\subsection{High Pressure EGR System}

The intake mass of compressor in this system is only the air mass of the three-cylinder. The admitted mass for the turbine is obtained by Eq. 23.

$$
\begin{gathered}
\dot{m}_{T U R B}=\left[\left(3 \dot{m}_{a r}+3 \dot{m}_{c o m b}\right)+\dot{m}_{E G R}\right](1 \\
-W G \%)(E G R \%)
\end{gathered}
$$

The output temperature of the air in the intercooler with recirculation gases is calculated by the mass and energy balance in the mixer; this is shown in Eq. 24. This temperature is the admission of the cylinder.

$$
\begin{aligned}
& T_{M i s t}= \\
& \frac{\dot{m}_{a r} c_{p, a r} T_{s i}+\dot{m}_{e g r} c_{p, e g r} T s_{e g r}}{\dot{m}_{a r} c_{p, a r}+\dot{m}_{e g r} c_{p, e g r}}
\end{aligned}
$$

\subsection{Modelling of $\mathrm{NO}_{\mathrm{x}}$ and CO Formation}

The mathematical model for chemical kinetic calculations involves the application of a numerical method to solve a system of an ordinary differential equation. Because specific methods present difficulties related to stability issues when a set of chemical kinetic equations is calculated, an implicit method was used to solve the ODE-system as presented by Lima [17]. The model was based on the Zeldovich model with 12 species and 22 chemical reactions.

\subsection{The Knocking Model}

The prediction model for knocking was formulated and calibrated via experimental data for an aspirated engine considering the variables of pressure, temperature, and fuel octane levels.

Phenomenological models generally employ a one-step reaction instead of detailed chemical kinetics, which results in very high computational costs. The model was based on the Knock Integral Method (KIM) [21], which uses a simplified model for the self-ignition delay time $(\tau)$ model, described in an Arrhenius type Eq. (25) [8].

$\tau=C_{1}(O N / 100) p^{-C_{2}} e^{C_{3} / T}$

where: $\mathrm{C}_{1}, \mathrm{C}_{2}$, and $\mathrm{C}_{3}$ are the parameters that depend on mixture composition and engine characteristics. In this work, these constants where 17.13,1.7, and 3400, respectively, as determined by Santos Jr [18]. A predictable knocking model for internal combustion engines (called the Livengood-Wu integral) is obtained in Eq. 26 [21], by integrating it from the close of the intake valve (FVA) until all air-fuel mixture is burned.
$I=\int_{t F V A}^{t f}\left(\frac{1}{\tau}\right)_{P, T} d t$

where: tFVA and tf refer to the moment at which the intake valve closes, and the end of the unburned mixture.

This study used the integral value (I) as an indicator of the probability of knocking occurrences as well as an indicator of the intensity of the knock. When $\mathrm{I}<1$ knocking does not occur, and when I $>1$ knocking occurs. However, it is not possible to reliably predict knocking occurrences when $I$ value approximate 1 , as in 0.95 and 1.05 , for example.

\section{Results}

The pressure and temperature ratings of the turbocharger system were all determined via the aforementioned equations. Table 1 shows the engine's geometric and operating parameters that were used. The adopted efficiency for the intercooler was $70 \%$, and $72.5 \%$ for the turbine and compressor performance respectively. These values were stipulated by considering the normal operational values of the equipment.

The results will be presented seeking to highlight the importance of the turbo intercooler (IC-T), the EGR LP and HP cooler (C-EGR) in the system, and to show their influence on performance parameters, knocking, and the formation of $\mathrm{NO}_{\mathrm{x}}$ and CO. Knocking occurs at the lowest revolutions, so most of the results presented will be for 1500rpm. However, some results will also be presented for 4500rpm. Another critical parameter is the percentage of recirculated gases, which varied from 5 to $15 \%$. The intake pressure and temperature of the gases in the turbine were chosen by typical experimental values. For $1500 \mathrm{rpm}$ the $\mathrm{T}_{3}$ is $900 \mathrm{~K}$ and $\mathrm{P} 3$ is 1.4 bar; for $4500 \mathrm{rpm}$ the values are $930 \mathrm{~K}$ and $6 \mathrm{bar}$. The increase in the combustion duration due to EGR were estimated from literature.

\subsection{The Type of EGR System and EGR\%}

The first study presents how variations in the percentage of the mass of (EGR\%) influence the performance parameters and the temperature and pressure of the turbocharger system for engine speed at $1500 \mathrm{rpm}$. A constant $20 \%$ of exhaust gas mass flow bypasses the turbine through the wastegate (WG\%).

The influence of the EGR system type (LP or HP) is more evident in the peak of the temperature, formation $\mathrm{NO}_{\mathrm{x}}$, and the performance parameters. The EGR\% influences the peak of cylinder pressure and the temperatures of burned and unburned gases. The temperature of unburned gases affects the knock tendency, and the temperature of burned gases affects the $\mathrm{NO}_{\mathrm{x}}$ formation. Figure 2 to Figure 5 shows the results for the indicated diagram, temperature of unburned and burned gases and $\mathrm{NO}_{\mathrm{x}}$ formation, as functions of crank angle, respectively.

Figure 2 shows that the curve of pressure versus volume doesn't change varying the EGR system (almost superposed curves). When EGR\% increases, the peak of pressure reduces and, the work per cycle also reduces. 
Table 1. Geometrical and Operating Parameters of the Engine.

\begin{tabular}{lll} 
Parameters & Values & Units \\
\hline Bore & 80 & $\mathrm{~mm}$ \\
Connecting rod & 128 & $\mathrm{~mm}$ \\
Stoke & 79.5 & $\mathrm{~mm}$ \\
Compression ration & 12 & \\
Combustion time & $\begin{array}{l}\text { Depend on EGR } \\
\text { and type engine }\end{array}$ & $\mathrm{o}$ \\
Fuel & E95h & \\
Air relative humidity & 60 & $\%$ \\
$\lambda$ & 1 & \\
T environment. & 25 & $\mathrm{~K}$ \\
P environment. & 101325 & $\mathrm{~Pa}$ \\
ON & 108.5 & \\
Compressor Efficiency & $75 \%$ & \\
Turbine Efficiency & $75 \%$ & \\
Mechanic Efficiency & $90 \%$ &
\end{tabular}

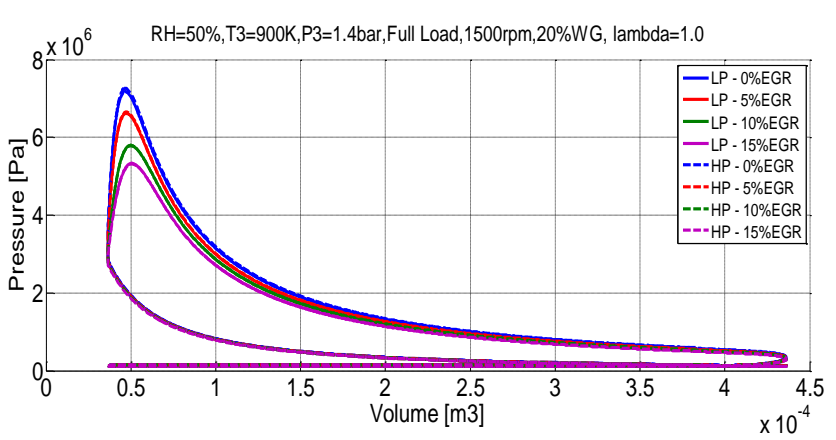

Figure 2. Influence of EGR type and EGR\% on the curve the pressure versus volume.

Figure 3 shows that the high pressure EGR system produces smaller temperatures in the unburned gases and reduces the knock tendency. As expected, when EGR\% increases, the temperature of unburned gases decreases. Fig.4 shows that the temperature of burned gases is highly affected by EGR\%. Higher temperatures in the burned gases increase the $\mathrm{NO}_{\mathrm{x}}$ emissions. The type of EGR system has a small effect on burned gases temperatures. The influence is more significant for EGR values above $10 \%$.

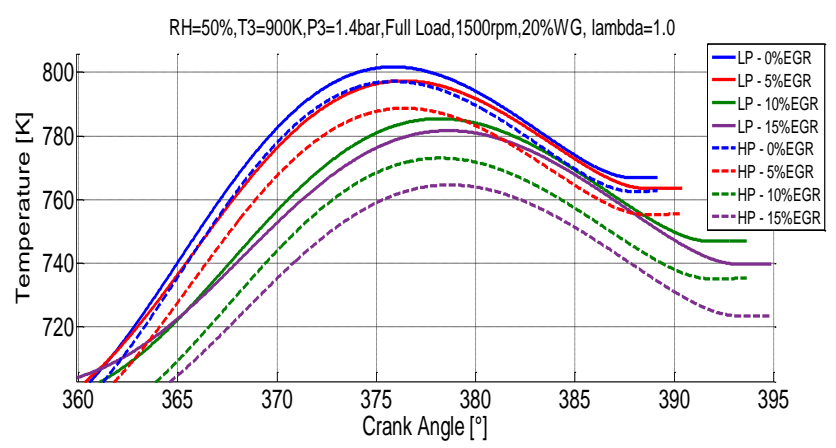

Figure 3. Influence of type of EGR system and EGR\% on the temperature of unburned gases.

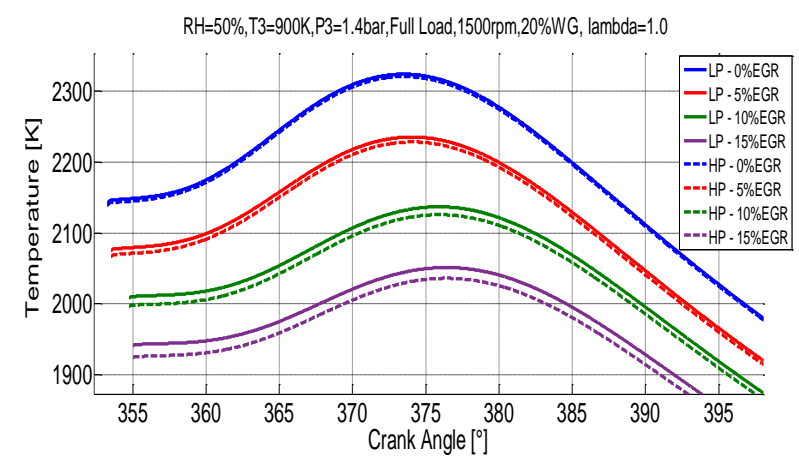

Figure 4. Influence of type of EGR system and EGR\% on the temperature of burned gases.

Figure 5 shows the concentration of $\mathrm{NO}_{\mathrm{x}}$ as a function of crank angle. The peak of $\mathrm{NO}_{\mathrm{x}}$ occurs near the peak temperatures. For high values of crank angle, the concentration of $\mathrm{NO}_{\mathrm{x}}$ is almost constant. When the exhaust valve opens (near $510^{\circ} \mathrm{CA}$ in this engine), this is the gross $\mathrm{NO}_{\mathrm{x}}$ emissions (before the three way catalyst). The reduction in the $\mathrm{NO}_{\mathrm{x}}$ emission is directly linked to the amount of recirculated gases. When there is less EGR\%, there is a greater formation of $\mathrm{NO}_{\mathrm{x}}$. The type of EGR system also affects, especially for higher EGR\%. The turbocharger operating with HP-EGR forms less $\mathrm{NO}_{x}$ than operating with the LP-EGR. The values of the formation $\mathrm{CO}$ are very close for all cases, so they will not be presented here. $\mathrm{CO}$ formation is a strong function for the air-fuel ratio.

Table 2 and Table 3 show the influence of the variation of EGR\% $(0,5,10,15 \%)$ on some performance parameters for LP-EGR and HP-EGR, respectively. The volumetric efficiency is greater than $100 \%$ since the density of the admitted mixture is higher than that of atmospheric air. The specific fuel consumption is for ethanol and can't be compared with specific fuel consumption for gasoline. If such comparison is desired, the thermal efficiency is also presented in the Tables. The results show that when the EGR\% is increased, the parameters of performance are deteriorated. However, the intensity of the knock engine, measured by the integral value (I), decreases considerably, taking the engine out of the knock zone. For 10\%EGR the value of the integral increase of $26 \%$ of LP-EGR and $32 \%$ for HP-EGR when compared with the 0\%EGR. For this conditions, the ideal amount of recirculation was $10 \%$, because the engine doesn't knock and the formation of $\mathrm{NO}_{\mathrm{x}}$ is the best when compared with a turbocharged engine without EGR and the power reduce in $16 \%$.

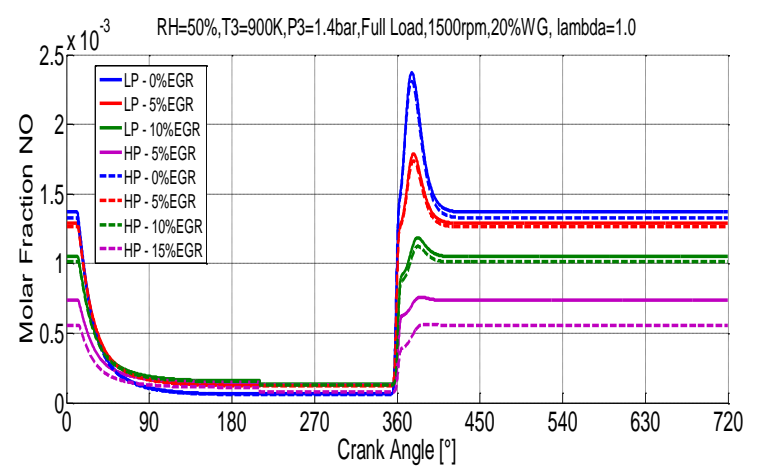

Figure 5. Influence of the EGR system and EGR\% in the $\mathrm{NO}_{x}$ emissions. 
Table 2. Results of the System Operating with LP EGR, Varying the EGR\% for $20 \% W G$.

\begin{tabular}{ccccc}
\hline EGR\% & 0 & 5 & 10 & 15 \\
\hline Power $[\mathrm{kW}]$ & 6.32 & 5.86 & 5.36 & 4.92 \\
Torque $[\mathrm{Nm}]$ & 40.26 & 37.30 & 34.12 & 31.31 \\
$\eta_{\mathrm{t}}[\%]$ & 38,01 & 37.69 & 37.06 & 36.73 \\
$\eta_{\mathrm{v}}[\%]$ & 120.66 & 119.08 & 117.55 & 115.81 \\
$\mathrm{sfc}[\mathrm{g} / \mathrm{kWh}]$ & 366.31 & 369.34 & 375.66 & 379.02 \\
Knock indicator & Yes & Yes/No & No & No \\
Value I & 1.18 & 1.06 & 0.88 & 0.79 \\
Combustion & 46.25 & 47.50 & 49.50 & 52.00 \\
Duration & & & & \\
\hline
\end{tabular}

When comparing the systems LP-EGR and HP-EGR systems the performance parameters are almost equal, but the HP-EGR has the best values of the power, for detonation tendency integral, thermal and volumetric efficiencies, and smaller formation the $\mathrm{NO}_{\mathrm{x}}$. The real gasoline turbocharged engine on which this ethanol simulation is based utilizes the HP EGR system. Then, the next results to be presented are limited to the HP-EGR system.

Table 3. Results of the System Operating with HP EGR, Varying the EGR\% for $20 \% W G$.

\begin{tabular}{ccccc}
\hline EGR $\%$ & 0 & 5 & 10 & 15 \\
\hline Power $[\mathrm{kW}]$ & 6.43 & 5.91 & 5.39 & 4.95 \\
Torque $[\mathrm{Nm}]$ & 40.92 & 37.63 & 34.32 & 31.52 \\
$\eta_{\mathrm{t}}[\%]$ & 38.05 & 37.70 & 37.04 & 36.71 \\
$\eta_{\mathrm{v}}[\%]$ & 120.68 & 118.57 & 116.67 & 115.02 \\
$\mathrm{sfc}[\mathrm{g} / \mathrm{kWh}]$ & 365.91 & 369.32 & 375.85 & 379.26 \\
$\quad$ Knock & Yes & Yes/No & No & No \\
indicator & 1.17 & 1.01 & 0.80 & 0.69 \\
$\begin{array}{c}\text { Value I } \\
\text { Combustion } \\
\text { Duration }\end{array}$ & 46.25 & 47.50 & 49.50 & 52.00 \\
\hline
\end{tabular}

The value of the knock indicator, the integral I, changes with the amount of the recirculation mass of gases and with the EGR type. Figure 6 presents as each EGR system influences the admission temperature for the engine, that is, the temperature of the mixture of the air with EGR available to the cylinder.

The difference between the admission temperatures of the EGR cooled, for 0\%EGR is lower when having more EGR. This difference for $15 \% \mathrm{EGR}$ is about $5 \%$. But the amplitude of the admission temperatures varies in the maximum $17 \mathrm{~K}$.

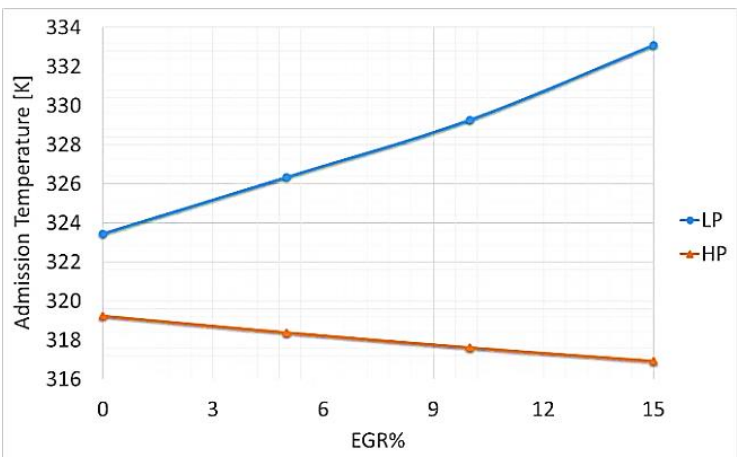

Figure 6. Influence of the EGR system in the engine admission temperature of the mixture air with EGR.

\subsection{Results of the Influence of the EGR Cooler and Turbo Intercooler (IC)}

The study of the importance of the IC and HP-EGR system was considered for an engine speed of 4500rpm, and for $5 \%$ and $20 \mathrm{WG} \%$ by comparing its values with those of an aspirated engine.

The first case analyzed considers the turbocharger utilizing the intercooler and cooled EGR (With ICs), which represents the base results. The second case adopts similar parameters of the previous case, the turbocharger hasn't intercooler, but has HP EGR cooled (without IC-T). In the third case the turbocharger simulated has an intercooler, but hasn't HP EGR cooler (without C-EGR). The last simulated case both coolers are absent (for turbocharger and HP EGR) and is identified as (Without ICs). These analyses were realized to study the influence of each type the equipment of the turbocharged engine performance.

Figure 7 shows the influence of the intercooler and the cooled for the HP-EGR in the curve the pressure versus volume and comparing with the naturally aspirated engine.

It is essential to highlight that the curves for case without the two coolers (Without ICs) overlap the curves of the case without the intercooler but with the cooled EGR (Without ICT). In a similar way, the curves of the case without the EGR cooler (Without C-EGR) and with the two coolers (With ICs) also overlap. This overlap demonstrates the influence of each equipment on the typical curves of an spark-ignition turbocharged engine.

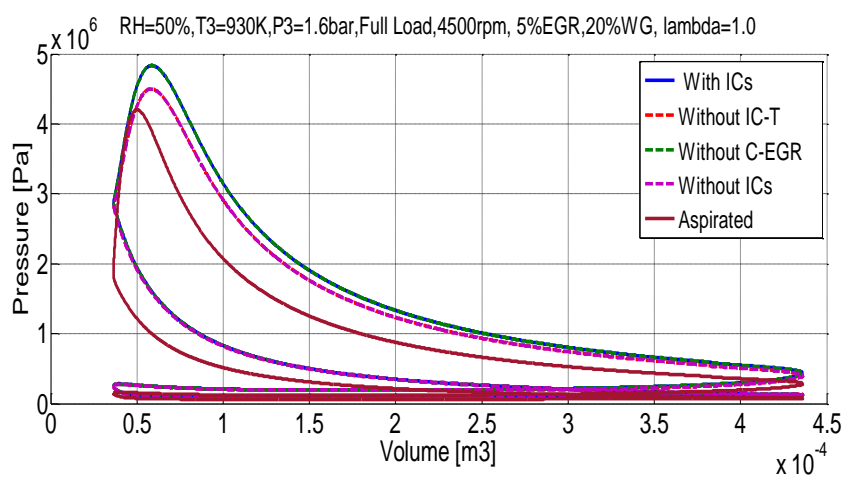

Figure 7. Comparison of the influence of the cooling equipment for turbocharged engine and the aspirated engine.

The results show that the aspirated engine has a smaller peak of pressure and area of the PV curve, as expected. The results of the first case simulated (with ICs) and the third case (without C-EGR) present superposed curves, that is, the cooler for EGR has a second order effect. The higher peak pressure and greater area in the diagram are for the intercooled turbo with cooled EGR (Figure 7). For this high engine speed, detonation is not a problem (see Table 4).

Figure 8 shows the mass inside the cylinder as a function of crank angle. The turbocharger engine with intercooler increases the mass inside the cylinder by nearly $50 \%$ when compared with the aspirated engine.

Figure 9 shows the mass flowing through the valves at the same previous conditions. The mass flow through the intake valve can be seen at the left portion of the Fig. 8 and for the exhaust valve at the right side. 


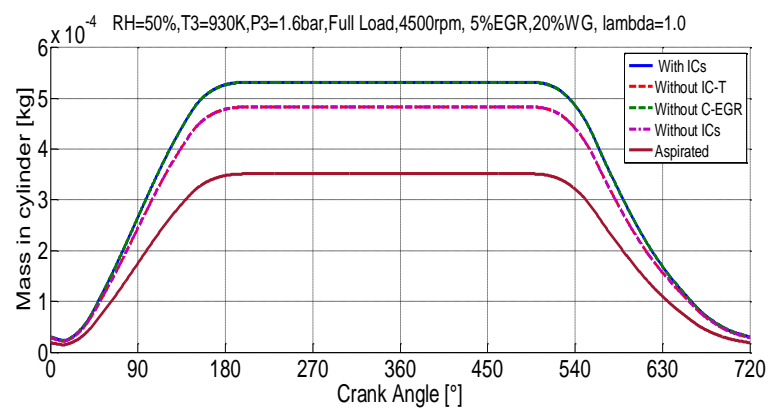

Figure 8. Comparison of the influence of the equipment in the mass inside the cylinder.

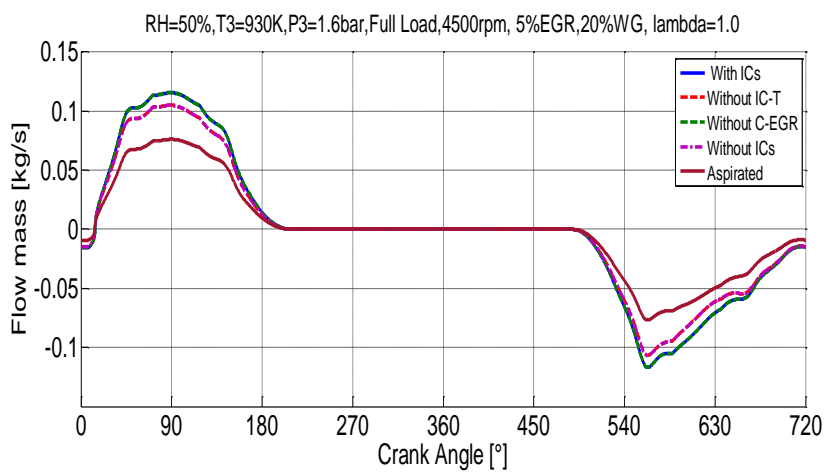

Figure 9. Comparison of the influence of the equipment in turbocharger engine with engine aspirated on the mass flow through valves.

The aspirated engine has higher formation $\mathrm{NO}_{\mathrm{x}}$ (Fig. 10) because this engine has a higher peak of the temperature of the burned gases (Fig. 11). The temperature and availability of oxygen are factors that induces the larger $\mathrm{NO}_{\mathrm{x}}$ formation. The turbocharged engine without cooled EGR create less $\mathrm{NO}_{\mathrm{x}}$ than without IC, about 19\%. Compared with the engine without EGR with aspirated, this value is about $45 \%$.

The curves of temperature for the burned gases (Fig. 11), and for unburned gases (Fig.12) show the same aspects of the others curves. The intercooler of the turbocharger engine has much more influence than the cooler of the EGR. But the peak temperature of the unburned gases without EGR cooler is larger than the aspirated engine, so this reflects in the value integral the knock, as the Table 4 show.

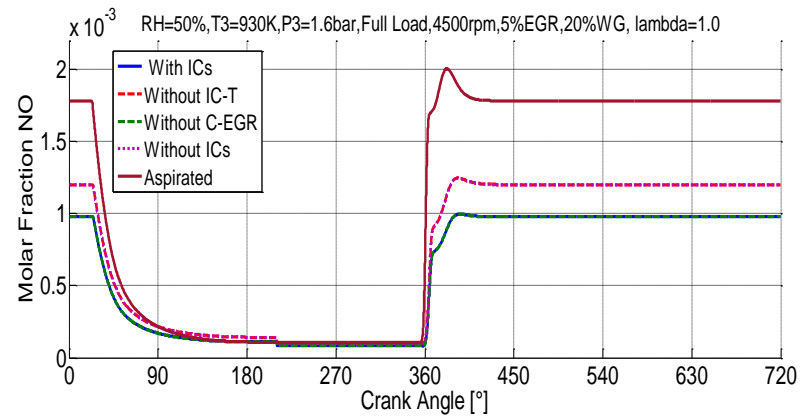

Figure 10. Comparison of the influence of the equipment on the $\mathrm{NO}_{x}$ formation.

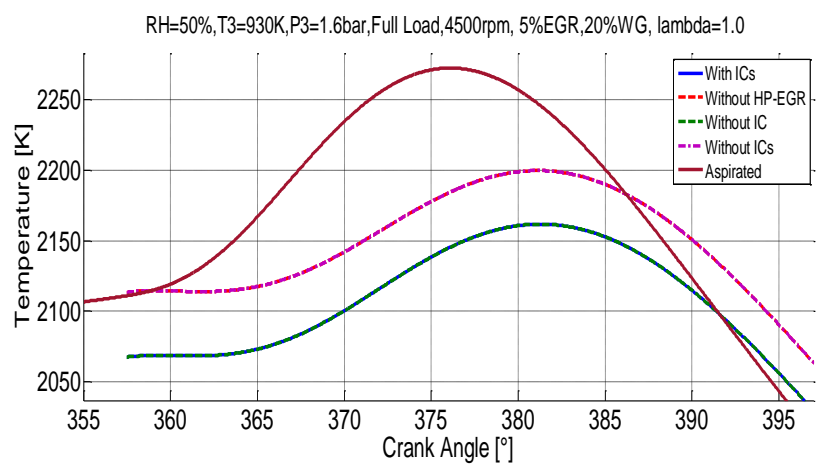

Figure 11. Comparison of the influence of the equipment on the temperature of the burned gases.

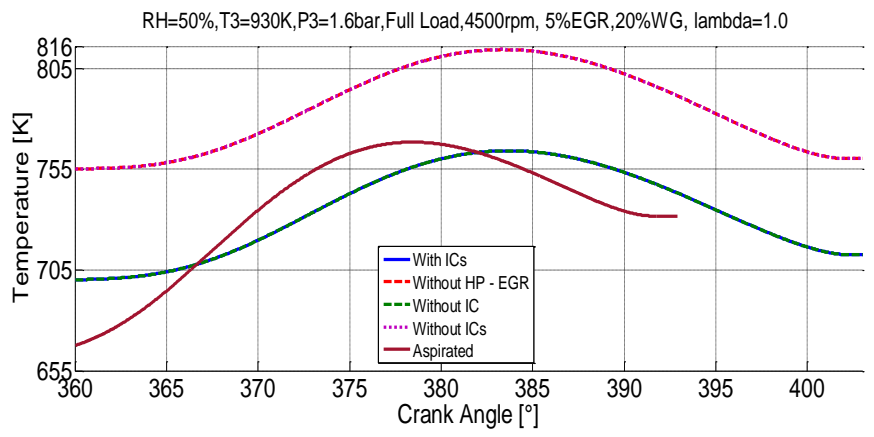

Figure 12. Comparison of the influence of the IC and cooler of HP-EGR on the temperature of the unburned gases.

Table 4. Results for Performance Parameters for the Aspirated and Turbocharged Engine in the Four Cases.

\begin{tabular}{cccccc}
\hline & $\begin{array}{c}\text { With } \\
\text { ICs }\end{array}$ & $\begin{array}{c}\text { Without } \\
\text { IC }\end{array}$ & $\begin{array}{c}\text { Without } \\
\text { C-EGR }\end{array}$ & $\begin{array}{c}\text { Without } \\
\text { ICs }\end{array}$ & Aspirated \\
\hline $\begin{array}{c}\text { Power } \\
{[\mathrm{kW}]}\end{array}$ & 15.2 & 13.7 & 15.2 & 13.7 & 11.4 \\
$\begin{array}{c}\text { Torque } \\
{[\mathrm{Nm}]}\end{array}$ & 32.2 & 29.0 & 32.2 & 29.0 & 24.2 \\
$\eta_{\mathrm{t}}[\%]$ & 33.0 & 32.9 & 33,0 & 32.91 & 35.5 \\
$\eta_{\mathrm{v}}[\%]$ & 117.8 & 107.0 & 117.8 & 107.0 & 77.6 \\
$\begin{array}{c}\mathrm{sfc} \\
{[\mathrm{g} / \mathrm{kWh}]}\end{array}$ & 421.3 & 422.9 & 421.3 & 422.9 & 391.6 \\
Knock & No & No & No & No & No \\
$\begin{array}{c}\text { indicator } \\
\text { Value I }\end{array}$ & 0.24 & 0.31 & 0.24 & 0.31 & 0.13 \\
\hline & & & & &
\end{tabular}

The results show the same tendencies of curves presented. The engine with turbocharger but without intercooler presents the same results than that of the engine without both IC and HP-EGR coolers. There is a $10 \%$ reduction in the performance parameters from the engine with IC and EGR coolers. The difference between performance parameters among the turbocharged engine with ICs and the aspirated engine is about $25 \%$.

\subsection{The combined Effects of the Waste-Gate Mass Flow, Intercooler and EGR Cooler}

To give a better analysis of the knock and the influence of the intercooler, the next results are for $1500 \mathrm{rpm}$, varying the WG\% and the engine with ICs and without IC. Figure 13 shows the instantaneous pressure as a function of the crank angle. 


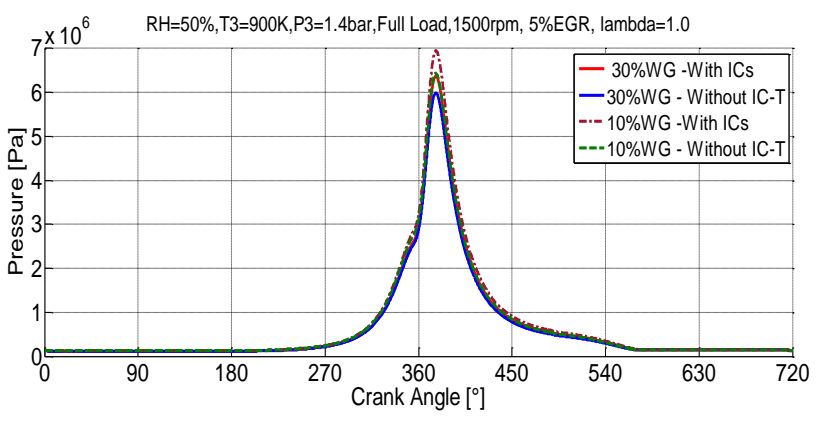

Figure 13. Influence the $W G \%$ and the intercooler in the curve the pressure versus crank angle.

The higher peak of pressure is for the engine turbocharged with $10 \%$ WG with ICs. The lower peak is $30 \%$ without IC, and the difference between the higher and the lower peak is about $14 \%$. The influence of the mass flow through the wastegate (10\%WG vs. $30 \% \mathrm{WG})$ in the peak pressure in the combustion chamber is about $8 \%$ for the engine turbocharged with ICs. For the engine turbocharged without IC, the difference of the peak pressure is about $7 \%$.

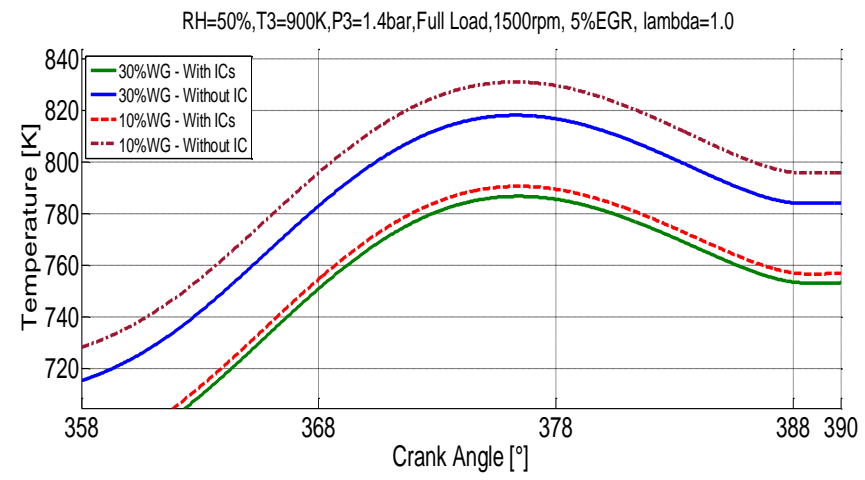

Figure 14 - Influence the mass flow through WG and the intercooler in the temperature of the unburned gases.

Figure 14 shows the temperature of the unburned gases. Higher WG\% reduces the turbine power, the compressor pressure ratio, and then the temperature of unburned gases. The presence of the turbo intercooler IC reduces the inlet temperature in the intake process, which also reduces the temperature of unburned gases. For the results in the Fig.14, there is a decrease of nearly 30 to $40 \mathrm{~K}$ due to the IC effect (present or not present). The effect of the $\mathrm{WG} \%$ is smaller, although present: from 5 to $12 \mathrm{~K}$.

The effects of the turbo intercooler and of the wastegate mass flow on the engine performance parameters are shown in Table 5, which indicate the huge importance of intercooler for knock control. With intercooler (IC), the value of integral (knock indicator) is lower than without IC, and with 30WG\% the engine is free of the knock.

For $10 \mathrm{WG} \%$, the difference between the engine with and without IC can be observed in the performance parameters. However, both cases indicate the engine must be knocking, but with IC, the knock intensity is lower.

Comparing the influence of the mass through the wastegate, when the WG\% increases, less mass pass through the turbine, the turbine power decreases, the pressure ratio in the compressor decreases and the engine power decreases. In the results presented in Table 5, the influence of $\mathrm{WG} \%$ for the engine with intercooler and cooled EGR is about $10 \%$. When the engine hasn't IC, the difference is about $8 \%$.
Table 5. Results of the performance parameters comparing $W G \%$ and the influence of intercooler.

\begin{tabular}{ccc|cc}
\hline \multicolumn{2}{c|}{30 WG\% } & \multicolumn{2}{c}{ 10WG\% } \\
\hline & With ICs & Without IC & With ICs & Without IC \\
$\begin{array}{c}\text { Power } \\
{[\mathrm{kW}]}\end{array}$ & 5.63 & 5.18 & 6.21 & 5.59 \\
Toque & 35.87 & 32.97 & 39.53 & 35.61 \\
{$[\mathrm{Nm}]$} & & & 37.91 & 37.63 \\
$\eta_{\mathrm{t}}[\%]$ & 37.53 & 37.25 & 123.55 & 112.52 \\
$\eta_{\mathrm{v}}[\%]$ & 113.85 & 105.67 & 367.27 & 369.95 \\
$\begin{array}{c}\mathrm{sfc} \\
{[\mathrm{g} / \mathrm{kWh}]}\end{array}$ & 371.22 & 373.78 & & \\
$\begin{array}{c}\text { Knock } \\
\text { indicator } \\
\text { Value I }\end{array}$ & No & Yes/No & Yes & Yes \\
\hline
\end{tabular}

\section{Conclusions}

The study showed the influence of the EGR mass percentage $(\mathrm{EGR} \%)$ and the wastegate mass percentage (WG\%) on a turbocharged engine operating with hydrated ethanol (E95h), consisting of a stoichiometric mixture under full load. Increasing the EGR\% and $\mathrm{WG} \%$, thermal efficiency and consumption did not suffer substantial variations, but emissions decreased as well as the knocking occurrence or intensity.

The use of the IC proved to be of great importance, as it significantly increased the power (7\% a $10 \%$ depending on the $\mathrm{WG} \%$ and EGR\%), torque, and volumetric efficiency when compared to turbo systems where it is absent. It also assisted in the reduction of $\mathrm{NO}_{\mathrm{x}}$ formation (more than $50 \%$ depending on $\mathrm{WG} \%$ and EGR\%) and decreased the intensity and frequency of engine knocking in turbocharged engines (10 a 13\% depending on the $\mathrm{WG} \%$ and $\mathrm{EGR} \%$ ).

The influence of the intercooler is higher on the temperature of the unburned gases, and consequently, the knocking phenomena, because a greater mass passes through it than does in the EGR cooler, thus cooling the intake mixture in the cylinder. The EGR, however, has a higher influence on the temperature of the burned gases and consequently on $\mathrm{NO}_{\mathrm{x}}$ formation and the HP-EGR presents better results in these parameters.

Problems such as engine knocking and elevated levels of $\mathrm{NO}_{\mathrm{x}}$ and $\mathrm{CO}$ emissions can be predicted with the model for any operational point of the engine, turbocharger, and EGR configuration.

This study has provided some results on ethanol turbocharged engines that are not yet available in the literature and can be driving the use of biofuels in vehicles more and more. Despite being a study based on a phenomenological model, the aspirated engine model was validated for ethanol and good results were obtained for the engine performance parameters, with maximum deviation of $7 \%$ from the experimental data. Some data used for the turbocharged engine model were estimated from previous experimental results for gasoline engines. The model was efficient in presenting solid trends of the results and enabling more studies for ethanol engines. This makes it possible to explore more operating conditions and even unproven technologies avoiding huge costs for different prototypes and lots of experimental tests, helping to direct resources to the more promising options. 


\section{Acknowledgments}

The authors would like to express their gratitude to their partnership with the PSA Peugeot Citroen Group. The authors also would like to express their gratitude to the Fundação de Amparo do Estado de São Paulo (FAPESP), for the financial support through the process number 2015/03170-0.

$\begin{array}{ll}\text { Nomenclature } & \\ \text { EGR } & \text { Exhaust Gas Recirculation } \\ \text { SI } & \text { Spark ignition } \\ \text { IC-T } & \text { Intercooler of turbocharger } \\ \text { HP } & \text { High pressure } \\ \text { LP } & \text { Low pressure } \\ \text { C }- \text { EGR } & \text { cooled EGR } \\ \text { With ICs } & \text { Engine turbocharged with intercooler and EGR } \\ & \text { cooler } \\ \text { Without IC } & \text { Engine turbocharged with only EGR cooled } \\ \text { Without C- EGR } & \text { Engine turbocharged with the only intercooler } \\ & \text { Engine turbocharged without an intercooler and } \\ \text { Without ICs } & \text { EGR cooled. } \\ & \text { Fraction mass through the valve wastegate [\%] } \\ \text { WG\% } & \text { Fraction mass of recirculation exhaust gases [\%] } \\ \text { EGR\% } & \text { Coefficient of the excess the air } \\ \lambda & \text { Thermal efficiency [\%] } \\ \eta_{\tau} & \text { Volumetric efficiency [\%] } \\ \eta_{\varpi} & \text { Pressure [Pa] } \\ \mathrm{P} & \text { Temperature [T] } \\ \mathrm{T} & \text { consumption specific fuel [kg/kWh] } \\ \mathrm{sfc} & \text { Indicator of the probability of knocking } \\ \mathrm{I} & \text { occurrences } \\ \text { E95h } & \text { Ethanol with 5\% of the water in volume } \\ \mathrm{NTU} & \text { Number of Transfer Units } \\ \varepsilon & \text { Effectiveness } \\ 1 & \text { Point before compressor } \\ 2 & \text { Point after compressor } \\ 3 & \text { Point before turbine } \\ 4 & \text { Point after turbine } \\ \mathrm{s}_{\mathrm{i}} & \text { Point after intercooler } \\ & \end{array}$

\section{References}

[1] C. Park, Y. Choi, C. Kim, S. Oh, G. Lim, and Y. Moriyoshi, "Performance and exhaust emission characteristics of a spark ignition engine using ethanol and ethanol-reformed gas," Fuel, vol. 89, no. 8, pp. 2118-2125, 2010.

[2] A. Boretti, "Analysis of desing of pure ethanol engines," SAE 2010-01-1453, pp. 1-13, 2010.

[3] L. Bromberg and D. R. Cohn, "Effective Octane and Efficiency advantages of direct injection alcohol engines," LFEE 2008-01, 2008.

[4] S. M. Sarathy, P. Oßwald, N. Hansen, and K. KohseHöinghaus, "Alcohol combustion chemistry," Prog. Energy Combust. Sci., vol. 44, pp. 40-102, Oct. 2014.

[5] C. Cuevas, D. Makaire, and P. Ngendakumana, "Thermo-hydraulic characterization of an automotive intercooler for a low pressure EGR application," Appl. Therm. Eng., vol. 31, no. 14-15, pp. 2474-2484, 2011.

[6] A. K. Agrawal, S. K. Singh, S. Sinha, and M. K. Shukla, "Effect of EGR on the Exhaust Gas Temperature and
Exhaust Opacity in Compression Ignition Engines," Appl. Mech. Mater., vol. 29, pp. 275-284, 2004.

[7] N. Ghassembaglou and L. Torkaman, "Efficient design of exhaust gas cooler in cold EGR equipped dies el engine," Alexandria Eng. J., vol. 55, no. 2, pp. 769-778, 2016.

[8] L. Chen, T. Li, T. Yin, and B. Zheng, "A predictive model for knock onset in spark-ignition engines with cooled EGR," Energy Convers. Manag., vol. 87, pp. 946-955, 2014.

[9] L. Bromberg, D. R. Cohn, and J. B. Heywood, "Calculations of knock suppression in highly turbocharged gasoline/ethanol engines using direct ethanol injection," Lfee, pp. 1-17, 2006.

[10] L. Chen, P. Sun, S. Ding, and S. Yang, "Miscibility of ternary systems containing kerosene-based surrogate fuel and hydrous ethanol: Experimental data+thermodynamic modeling," Fluid Phase Equilibria, vol. 379, Elsevier B.V., pp. 1-9, Oct-2014.

[11] T. Alger, "Cooled exhaust-gas recirculation for fuel economy and emissions improvement in gasoline engines," Int. J. Engine Res., vol. 12, no. 3, pp. 252-264, 2011.

[12] A. P. Mattos, Estudo do desempenho de um motor turboalimentado a etanol empregando EGR para redução de emissões de NO x e controle de Estudo do desempenho de um motor turbo- alimentado a etanol empregando EGR para redução de emissões de NOx e controle detonação, UNICAMP, (Doctoral dissertation), 2018.

[13] Y. Jamal, T. Wagner, and M. L. Wyszynski, "Exhaust gas reforming of gasoline at moderate temperatures," International Journal of Hydrogen Energy, vol. 21, no. 6, pp. 507-519, 1996.

[14] W. W. Pulkrabek, Engineering Fundamentals of the Internal Combustion Engine, $2^{\text {nd }}$ Ed. New Jersey: Prentice Hall, 1997.

[15] P. Moulin, J. Chauvin, and B. Youssef, "Modelling and control of the air system of a turbocharged gasoline engine," in The internation Federation of Automatic Control, 2008.

[16] A. J. T. B. de L. Lima, Pollutant Formation Simulation Models ( $\mathrm{CO}$, NOx and UHC ) for Ethanol-fueled Engines, (Master dissertation in portuguese), Universidade Estadual de Campinas, 2017.

[17] F. R. D. S. Júnior, Estudo de um modelo computacional para prever a ocorrência da detonação em um motor avançado a etanol, (Master dissertation), Univeridade Estadual de Campinas, 2017.

[18] M. W. Chase, J. R. Davies, J. Downey, D. J. Frurip, R. A. McDonald, and A. N. Syverud, JANAF Thermochemical Tables, $3^{\text {rd }}$ Ed. US \& Canada: American chemical society and the American Institute of Physisics for National Bureau of Standards, 1985.

[19] A. Y. Cengel, Transfereência de calor e massa. Uma abordagem prática., $3^{\text {rd }}$ Ed. São Paulo: McGraw-Hill, 2009.

[20] A. M. Douaud and P. Eyzat, "Four Octane Number Method for predicting the anti-knock behavior of fuel and engines," SAE 780080, 1979. 